\title{
A voice for tech workers
}

\author{
The reach of artificial intelligence technologies across all parts of society is steadily growing, but so is the \\ awareness of how they can negatively impact human rights. As 2019 draws to a close, the trajectory of \\ technological progress defined by big technology companies is meeting resistance.
}

T his year has shown that pushback against powerful and potentially harmful AI technologies can be successful. There is much debate around the use of facial recognition in surveillance applications. After protests from humanrights groups and calls from politicians, government bans on facial recognition are now in place in four major US cities. Within big technology companies such as Google, Microsoft and Amazon, a growing movement of workers are raising the alarm over the possible harmful impact of their companies' products and services. Earlier this year, a group called Googlers for Human Rights urged Google to back away from bidding for a cloud computing contract that involved processing immigrant data for the US Immigration and Customs Enforcement agency (ICE). ICE has been widely criticized over multiple incidents of inhumane treatment of immigrants, including children. In 2018, several employees resigned and around 4,000 of them signed a petition in protest against Google's involvement in another US government project, Project Maven, which analyses drone footage and identifies potential strike targets. Google withdrew from the collaboration. A few months later, Google backed out of bidding for the US Department of Defense's Joint Enterprise Defense Infrastructure (JEDI) contract, a US $\$ 10$ billion cloud infrastructure project.

Also this year, over 8,500 Amazon employees mobilized and called upon the company to face up to its contribution to climate change. In an open letter, CEO Jeff Bezos and directors were urged to formulate a comprehensive climate plan. Under threat of a massive walkout, Bezos announced a climate pledge on 19 September in which he committed to net-zero carbon emissions for the company by 2040 .

But such employee-led campaigns are not always successful. GitHub, the code and software repository owned since mid-2018 by Microsoft, recently saw several employees resign over their own contract with ICE.
In a recent memo, GitHub CEO Nat Friedman pledged to donate US $\$ 500,000$ to charities that support immigrants, which is remarkable as the contract itself is worth US\$200,000. However, this move drew further criticism from employees, who argued in an open letter that money cannot offset human lives. Amazon and Microsoft employees have also asked their CEOs to cut ties with ICE. The JEDI contract was eventually awarded to Microsoft, despite internal protests from their workers.

Silicon Valley has a rich history of working on government and military projects, starting with the Second World War. And the issues can be complex: technologies that can potentially be used for harm can also save lives. In the aforesaid memo, GitHub CEO Friedman argues that software technologies "could be used in projects that support policies we both agree and disagree with", pointing out that, for instance, ICE can employ Github's services in the fight against human trafficking. According to Friedman, companies should advocate their values in a democracy by using their corporate voice, not by unplugging technology. Brad Smith, the president of Microsoft, made a similar point last year in response to the debate over whether Microsoft should bid for JEDI, arguing that the company should use its knowledge and voice as a corporate citizen to address ethics concerns over AI technology in weapons and warfare through the country's democratic processes. An underlying argument is that companies are providing a tool or service to government parties that have been elected by the public: it's the government that holds the ultimate responsibility for use of technology.

However, many researchers and tech workers have realized that separating basic technology development and real-world applications in this way can become an untenable position. The petition from Google employees last year asking the company to withdraw from Project Maven opened with "We believe that Google should not be in the business of war" and argued that moral responsibility for the technologies the company develops should not be outsourced. In a BBC interview, former Google employee Laura Nolan explains how she understood that she would ultimately have been part of a 'kill chain' while working on Google Cloud infrastructure for Project Maven. She went on to contribute to the Campaign to Stop Killer Robots, a coalition of NGOs that works towards a full, worldwide ban on autonomous weapons.

There is a rich history of tech workers in Silicon Valley organizing to campaign against potentially harmful projects, often demanding a genuinely democratic say in how technologies are developed and used. Their in-demand skillset promises a powerful opportunity for them to achieve such influence. Many tech workers view themselves as politically progressive, and joined the industry because they genuinely believed in its power to bring positive change to the world. Their collective power has the potential to forge positive change from the inside.

But there are significant challenges to employees' movements, especially as there are signs that companies are attempting to curb organized internal protests and are making a move towards less transparency in executive decisions. It will be up to movements such as The Tech Workers Coalition, which was formed in 2014 and evolved into an initiative to empower tech workers who want more say in their companies' decisions, to give a strong voice to workers across the industry and to strive towards long-term success.

In 2020, the growing movement of workers in powerful technology companies must continue to push towards a more democratic, inclusive and transparent development of AI technologies that are safe and bring benefits for all.

Published online: 10 December 2019 https://doi.org/10.1038/s42256-019-0131-3 